\title{
Meaning in Life, Psychological Well-Being and Depressive Symptomatology: A Comparative Study
}

\author{
George Kleftaras, Evangelia Psarra \\ Department of Special Education, University of Thessaly, Volos, Greece \\ Email: gkleftaras@uth.gr
}

Received January $26^{\text {th }}, 2012$; revised February $24^{\text {th }}, 2012$; accepted March $27^{\text {th }}, 2012$

\begin{abstract}
The purpose of the present study was to examine the relationship of meaning in life and its dimensions to depression and general psychological health, as well as the differences concerning the meaning of life among individuals with low, moderate and high depressive symptomatology. A sample of 401 newly recruited young men for their national service in the navy, completed four questionnaires on meaning in life, depressive symptomatology, psychological health and socio-demographic factors. Significant associations were found between meaning in life and depressive symptoms. As expected, subjects with higher life meaning were found to have lower depressive symptomatology, while subjects with higher depression scores were found to have a lower sense of meaning in life. However, concerning the meaning in life dimensions, only the "contentedness with life" and the "goal achievement" significantly differentiated individuals of low, moderate and high depressive symptomatology. Furthermore, statistical significant correlations were found between meaning in life and the four dimensions of general health. In the same vein, the comparison between individuals with the lower and the higher meaning of life has shown that the two groups differ significantly with regards to psychological health: those with higher meaning of life present a better psychological health. Finally, being married or involved in a romantic relationship, as well as participation in social activities are proven to be significant sources of meaning. These findings point to a definite relationship of meaning in life with depression and psychological health. Implications for psychotherapy and counselling are discussed.
\end{abstract}

Keywords: Meaning in Life; Depressive Symptomatology; Psychological Health

\section{Introduction}

The primary motive of human behavior, according to Frankl's existential theory (1959) is the will to meaning or else a person's strive to find a reason for his/her limited and often "confusing" existence. The meaning of life differs from person to person and from moment to moment. Thus, it cannot be defined in a general way. Human beings experience the meaning of life when they correspond in time to the demands of the situation they are in, when they discover and undertake their own unique duty in life and when they allow themselves to experience or believe in an ultimate meaning, which may refer to, among others, the faith in God. The choice of a person to be dedicated to a purpose outside of him/herself and to engage and contribute to the world are also emphasized. A person can discover his/her personal meaning of life (Frankl, 1973) by: 1) his/her creative values, which s/he experiences through goal achievement and what $\mathrm{s}$ /he contributes to life (e.g., work, creating a home, defending of a belief etc.); 2) his experiental values, which he experiences through anything good, beautiful or true he takes from life (e.g., enjoy music or a landscape, making an intimate relationship with another person) and 3) attitudinal values, which he experiences through the attitude he holds in a difficult situation or a situation which is inevitably accompanied by suffering. This attitude is indicative of a person's deeper perception for life and the world.

Meaning of life is a vital element that gives coherence to the person's worldview and a critical factor for his/her psychologi- cal and spiritual well-being. Frankl notes that life has meaning under all circumstances and that it is psychologically damaging when a person's search for meaning is hindered. If someone does not strive to find meaning in his/her life, then sooner or later he will lose his psychological well-being (Frankl, 1967, 1969). Meaninglessness causes a situation called "existential vacuum". This state can be manifested with symptoms of boredom, depression and/or aggressive behavior. Maddi (1967) has been referred to this situation with the term "existential neurosis", which is differentiated by depression in that it is more closely associated with apathy and less with depressive feeling.

In general, meaning of life has been positively associated with physical/psychological health/well-being and psychopathology and seems to serve as a mediator factor in psychologycal health (Chan, 2009; Fox \& Leung, 2009; Halama \& Dedova, 2007; Ho, Cheung, \& Cheung, 2010; Holahan, Holahan, \& Suzuki, 2008; Owens, Steger, Whitesell, \& Herrera, 2009) and death acceptance/fear of death (Routledge \& Juhl, 2010; Thompson, Noone, \& Guarino, 2003). Additionally, people who can find meaning in negative experiences, such as cancer (Jaarsma, Pool, Ranchor, \& Sanderman, 2007; Lethborg, Aranda, Cox, \& Kissane, 2007; Visser, Garssen, \& Vingerhoets, 2010), HIV (Lyon, 1997; Lyon \& Younger, 2001) or the loss of a child (Coyle, 1998), seem, after the incident, to cope better with the situation, in comparison to those that cannot find meaning.

The concepts of meaning in life, psychological well-being and depression are influenced by cultural factors. Culture in 
mental health care is a multifaceted concept and it can be seen as a dynamic process that links the past to the present and is shaped in part by social, historical, and political forces. Culture is more diverse than race or ethnicity and extends to other areas that tend to receive different and less attention than that received by the dominant culture, such as language, gender, class, age, sexual orientation, and religion (Waite \& Calamaro, 2009). The cultural factors are important not only among eastern and western societies but even for European multicultural society, because despite the indisputable similarities, there are, also, important and fundamental differences among the northern, central and southern countries forming the European Union.

When examining depression within different European countries, culture may be integral to improve detection, intervention, and recovery efforts for young men in different European countries, due to significant differences in social, political, financial, historical, ethnic and cultural backgrounds and especially in Greece, which seems to be in the midpoint between east and west. An interesting study, for instance, based on data collected in 14 nations in Europe ( $\mathrm{N}=3438$ female and 2091 male students; aged 17 - 30 years), has shown that soft or feminine nations, in which both women and men are offered equal opportunities for the fulfillment of multiple social roles that are associated with good self-rated health, would score significantly lower on national depression levels than tough or masculine societies in which such opportunities exist to a clearly lesser extent (Arrindell, Steptoe, \& Wardle, 2003).

Age is an important cultural factor, given that men in late adolescence often experience a stressful time of transition as they try to gain emotional independence. The ages between 18 and 25 years represent the final transition from childhood to adulthood, encompassing the end of adolescence and the achievement of full adult status. In these critical years, people's perceptions about themselves and their world are shaped and reshaped. Included in these perceptions are cultural values and beliefs regarding health and mental health (Kendricks, Anderson, \& Moore, 2007). Research reports that $25 \%$ of young adults, the highest incidence rate of any adult age group, experience a depressive episode by age 24 years (Kessler \& Walters, 1998; Klerman, 1988; Klerman \& Weissman, 1989). However, literature and research that examines psychological wellbeing and especially depression among men has received relatively little attention, in part, because the condition is often associated with being a woman (Prior, 1999). Young men affected by depression during this critical period are at increased risk of substance abuse, impaired work and relationship function, and negative influences on the individual's subsequent development (Reinherz, Giaconia, Hauf, Wasserman, \& Paradis, $2000)$. Moreover, fewer than $20 \%$ of young adults with depression, which has significant implications for suicide, receive high-quality care (Young, Klap, Sherbourne, \& Wells, 2001). Undiagnosed depressed mood and associated suicidal risk among youths have been greatest among young white men (Centers for Disease Control and Prevention, 2000).

The studies that have investigated the relationship of meaning in life with psychological well-being and depression are relatively few, and in general they demonstrate significant negative relationships among these variables. However, they have been conducted in the United States of America and with specific populations such as individuals with multiple sclerosis (Hart, Fonareva, Merluzzi, \& Mohr, 2005), HIV (Lyon \& Younger, 2001), cancer (Simonelli, Fowler, Maxwell, \& An- dersen, 2008), Schizophrenia (Stolovy, Lev-Wiesel, Adiel, \& Gelkopf, 2009), older adults (Westerhof et al., 2010) and college students (Mascaro \& Rosen, 2005, 2008; Robak \& Griffin, 2000). The need for further investigation of the relationship of meaning in life with depression and psychological well-being in other populations and in other sociocultural environments, such as the European one and more specifically the one of Greece, is necessary and becomes even more important, if we consider that depression is closely connected with suicidal ideation and mortality, which seem to be mediated by the concept of hopelessness. An intense feeling of depression may cause meaninglessness, which may in turn lead to suicidal ideation. The opposite, however, may be more possible, in the sense that meaninglessness may affect twofold suicidal behavior in both an indirect way, due to depression that may cause and in a direct way, due to the fact that life and its difficulties seem meaningless (Fitzpatrick, 2009; Heisel \& Flett, 2004; Kang, Shim, Jeon, \& Koh, 2009; Krause, 2009; Robak \& Griffin, 2000; Yang, Staps, \& Hijmans, 2010).

The aim of the present study is to help to the better understanding of subjective well-being and depressive symptommatology of young men in Greece and mainly of their relationships with meaning of life, which, according to the literature, seems to play a critical role in psychological health. In general, international studies regarding meaning of life, and its relationship with psychological well-being and depression are relatively few, especially in the population of young men, and mainly conducted in North America, while in Greece the relevant studies are non-existent, which rises caution as to the generalizability of their results to the specific sociocultural context of Greece. In the light of the above, the present research study aims at the evaluation of the subjective well-being and the severity of depression in the population of newly recruited young men for their national service in the Greek Army Navy, regarding the general meaning of life they experience, which eventually determines their attitude towards the difficulties they face. This population is considered vulnerable to both depressive symptomatology, and sucidal behavior, due to stressors, which these young men are going through during their first basic military training in the Army Navy (abrupt separation from family and friends for a month, change of their daily schedule and adaptation to a new context with stricter rules) (Florkowski, Gruszczynski, \& Wawrzyniak, 2001; James, 1993).

Finally, the investigation of the relationships between meaning of life and depressive symptomatology with socio-demographic variables, such as age, having a brother/sister, educational level and chiefly marital status and participation in cultural, athletic, political or other activities, is of much interest. Especially, regarding marital status and participation in several activities, we expect a significant positive relationship with meaning of life and a negative one with depression, as they may potentially serve as sources of meaning.

\section{Method}

\section{Subjects and Procedure}

The sample of the present study consisted of 401 newly recruited men during their basic training in Army Navy, who voluntarily participated in the present study, aged 18 - 30 years, with a mean age of 24.5 years. The majority $(82.8 \%)$ has either a University degree or a degree from Technological Institute. 
The sample's socio-demographic characteristics are illustrated in Table 1.

The research took place at the Training Center of the Army Navy in the island of Poros. Initially, subjects were informed about the material, the duration of the whole procedure and the anonymity of their participation and they were asked as to whether or not they would like, voluntarily, to participate in the study. Those who accepted, they were divided into two groups, each of 250 individuals, in order to complete the questionnaires of the study. Among the 464 completed questionnaires, only 401 were correctly filled.

\section{Measures}

In this study, except for the questions concerning the subjects' demographic characteristics, three questionnaires were administered:

1) Questionnaire of Self Evaluated Depressive Symptomatology (QD2). The QD2 is a 52-item self-report that taps a variety of the affective, cognitive and somatic symptoms of depresssion. The items are answered true or false. Higher scores indicate more severe levels of depression. This questionnaire was

Table 1.

Socio-demographic characteristics of the sample $(\mathrm{N}=401)$.

\begin{tabular}{|c|c|c|}
\hline & $\mathbf{N}$ & Relative Frequencies (\%) \\
\hline \multicolumn{3}{|l|}{ Age } \\
\hline $18-20$ & 23 & 5.8 \\
\hline $21-24$ & 159 & 39.9 \\
\hline $25-28$ & 202 & 50.8 \\
\hline $29+$ & 14 & 3.5 \\
\hline \multicolumn{3}{|l|}{ Educational level } \\
\hline Primary School & 1 & 0.3 \\
\hline Junior High School/S.E.I. ${ }^{1}$ & 19 & 4.8 \\
\hline Senior High School & 48 & 12.0 \\
\hline University & 332 & 82.8 \\
\hline \multicolumn{3}{|l|}{ Marital status } \\
\hline Single & 194 & 48.5 \\
\hline Married & 195 & 48.8 \\
\hline I have an affair & 11 & 2.8 \\
\hline \multicolumn{3}{|l|}{ Order of birth } \\
\hline First & 201 & 51.1 \\
\hline Second & 145 & 36.9 \\
\hline Third & 35 & 8.9 \\
\hline Fourth & 7 & 1.8 \\
\hline Fifth+ & 5 & 1.3 \\
\hline \multicolumn{3}{|l|}{ Participation in activities } \\
\hline Never & 45 & 11.3 \\
\hline Sometimes & 156 & 39.1 \\
\hline Often & 156 & 39.1 \\
\hline Always & 42 & 10.6 \\
\hline
\end{tabular}

${ }^{1}$ Secondary Technological School. constructed and validated by Pichot et al. (1984) in France. In fact, QD2 derived from the content analysis of the items of the four best known self report inventories exploring the symptoms experienced by depressive patients: the Hopkins Symptoms Check List, the French version of the Beck Depression Inventory (BDI), the Depression Scale of the Minnesota Multiphasic Personality Inventory (MMPI-D) and the Zung Self-Rating Depression Scale (SDS).

The QD2 has 1) a good homogeneity (studied by computing the phi $[\Phi]$ coefficient for each item: all coefficients were significant to .01 level of significance except from two which were significant to .05 level of significance); 2) a good reliability (split-half method; Spearman-Brown formula) studied in four groups of depressed (.93, $\mathrm{N}=157)$, normal $(.92, \mathrm{~N}=89)$, organic (.95, $\mathrm{N}=90)$ and psychiatric patients $(.94, \mathrm{~N}=145) ; 3)$ a good concurrent validity according to three criteria: contrasts between groups of depressed and non-depressed subjects (normal, organic and psychiatric patients), correlation with Zung Questionnaire, correlation with the intensity of depression as rated clinically; and 4) a satisfactory factorial structure. The responses of a group of clinically depressed patients $(\mathrm{N}=157)$ to QD2 were subjected to factor analysis which revealed three basic dimensions (factors), which correspond respectively to the feelings of loss of general drive, to the depressive-pessimistic mood, and to anxiety.

The QD2 was translated and adapted in Greek by a team of three bilingual psychologists (Kleftaras \& Tzonichaki, 2012). The factorial structure of the Greek version of QD2, as studied in both our sample and a population of young and elderly individuals (Kleftaras \& Tzonichaki, 2010; Tzonichaki \& Kleftaras, 1998), proved satisfactory and confirms the results of the relevant studies in France (Kleftaras, 1991, 2000; Pichot et al., 1984). The reliability coefficients of the Greek version of QD2, as found in the present study are .92 (Cronbach's a) and .91 (split-half reliability).

2) Purpose in Life Test (PIL). Crumbaugh \& Maholick's PIL test $(1964,1969)$ consists of 20 items, each rated on its own separately labeled seven-point Likert scale and scores can range from 20 to 140. This scale measures the degree to which a person experiences a sense of meaning in his life, as defined by Frankl's existential theory. The higher an individual's score on PIL, the higher the sense of meaning of life experienced by the individual.

According to relevant studies, PIL demonstrates a good reliability and validity according to split-half $(.87-.92)$ and test-retest method (.79 - .83) (Crumbaugh, 1968; Crumbaugh \& Maholick, 1964; Meier \& Edwards, 1974; Reker \& Cousins, 1979). PIL has also significant correlations with psychological health, well-being and social attitudes (Chan, 2009; Halama \& Dedova, 2007; Ho et al., 2010; Holahan et al., 2008; Lethborg et al., 2007; Jaarsma et al., 2007; Visser et al., 2010). Regarding the factorial analysis of PIL test, some studies have concluded that PIL test is a uni-dimensional scale (Garfield, 1973; Zeitchik, 2001), while others have found that the questionnaire contains more than one dimensions (Chamberlain \& Zika, 1988; Harlow, Newcomb, \& Bentler, 1986; Shek, 1992).

The PIL was translated, adapted into Greek and revised through back-translations by a team of 3 bilingual psychologists. The reliability of the Greek version of PIL test, according to Cronbach's $\alpha$ (alpha) coefficient is .89 , while the split half method reaches a coefficient of .88 . Finally, as it will be discussed next, its factorial structure, as studied in our sample, is 
satisfying and confirms the results of relevant studies in other countries (Kleftaras \& Psarra, 2012, in press).

3) General Health Questionnaire (GHQ) (Goldberg \& Hillier, 1979). The Greek version of GHQ, translated, adapted and validated in Greek by Garyfallos, Karastergiou and Adamopoulou (1991), consists of 28 items, assessing four factors: 1) somatic symptoms; 2) anxiety/sleep disturbances; 3) social dysfunction and 4) symptoms of severe depression, mainly on a cognitive level. Each factor can be assessed separately and the total score is considered as an indicator of a person's general psychological health. The GHQ is a measure of current mental health, as it asks whether the respondents have experienced a particular symptom or behaviour recently. It is a self-administered questionnaire and each item is rated on a four-point scale (less than usual, no more than usual, rather more than usual, or much more than usual). The higher the score, the more severe the health situation.

GHQ has a very good split half reliability $(r=.95)$, as well as internal consistency and reliability with Cronbach's $\alpha$ coefficients, ranging from $.77-.93$ for its sub-scales (Goldberg \& Williams, 1988). Furthermore, regarding GHQ's reliability, Goldberg and Williams (1988) report a variety of studies, in which the GHQ scores have relatively high correlations with scales assessing depression (Pearson $r=.57-.72$ ), quality of life, life satisfaction and psychosomatic symptoms, as well as structured clinical interviews, assessing general psychopathology $(r=.45$ - .83). These associations render GHQ a reliable psychometric instrument of the person's psychological health (Goldberg \& Williams, 1988).

\section{Results}

In the series of statistical analyses, performed in order to investigate the hypotheses of this study, the total scores of the participants in the questionnaires of depression and general health were used, due to the fact that previous studies in Greece have shown that the factorial structure and the reliability of these questionnaires are satisfactory (Garyfallos et al., 1991; Kleftaras \& Tzonichaki, 2010; Kleftaras \& Psarra, 2012, in press; Tzonichaki \& Kleftaras, 1998). However, regarding meaning of life and its dimensions, the subjects' scores in the first principal component (general factor-principal component analysis) were used for more precision, as well as their scores at the four factors extracted from the factorial analysis after orthogonal Varimax rotations. Specifically, the Purpose in Life Test has proven to be homogeneous and according to the "principal component analysis" it is composed of a general factor $\left(1^{\text {st }}\right.$ principal component: eigenvalue $=7.9$, explains $39.50 \%$ of the total variance), which is defined as "general factor of meaning of life", while orthogonal Varimax rotations produced the expected factors: 1) "contentedness with life" (eigenvalue $=4.57$, accounting for $22.89 \%$ of the total variance); 2 ) "goal achievement" (eigenvalue $=4.04$, accounting for $20.20 \%$ of total variance); 3 ) "freedom of choice" (eigenvalue $=1.36$, accounting for $6.83 \%$ of total variance) and d) "death" (eigenvalue $=1.13$, accounting for $5.66 \%$ of total variance) (Kleftaras \& Psarra, in press).

Initially, the relationship of the concept of meaning of life and its dimensions with depressive symptomatology was studied. The results indicate statistically significant negative correlations between the level of an individual's depressive symptomatology and 1) the total meaning of life that he experiences $(\mathrm{r}=-.55, \mathrm{p}<.0001) ; 2)$ contentedness with life that he feels $(\mathrm{r}$ $=-.46, \mathrm{p}<.0001) ; 3)$ the achievement of goals that he strives for $(\mathrm{r}=-.31, \mathrm{p}<.0001)$ and 4$)$ the freedom of choice that he perceives to have $(\mathrm{r}=-.08, \mathrm{p}<.05)$. On the contrary, a statistically significant correlation between depressive symptomatology and preoccupation with the concept of death $(\mathrm{r}=-.03, \mathrm{p}$ $>$.05) (Table 2), does not seem to exist.

Moreover, in order to investigate how the concept of meaning of life and especially its dimensions discriminate among the individuals of different depressive symptomatology, the sample was divided into three groups. The first group consists of 146 individuals with the lower depressive symptomatology (M $=.82, \mathrm{SD}=.84)$, the second group of 118 individuals with the higher depressive symptomatology $(\mathrm{M}=17.95, \mathrm{SD}=7.43)$ and finally the third group of 137 individuals with moderate levels of depression $(\mathrm{M}=5.60, \mathrm{SD}=1.92)$ compared to the other two groups. According to Table 3, the means of these three groups

Table 2.

Pearson's correlations between meaning of life and depressive symptomatology.

\begin{tabular}{cl}
\hline & Depression \\
\hline Meaning of Life & $-.46^{* * * *}$ \\
Contentedness with life & $-.31^{* * * *}$ \\
Goal achievement & $-.08^{*}$ \\
Freedom of choice & -.03 \\
Death & $-.55^{* * * *}$ \\
\hline
\end{tabular}

Note: ${ }^{*} p<.05,{ }^{* * * *} p<.0001$.

Table 3.

Comparison (One-Way ANOVA) of means (M) and standard deviations (SD) regarding meaning of life among persons with low, moderate and high depressive symptomatology.

\begin{tabular}{|c|c|c|c|c|}
\hline & \multicolumn{3}{|c|}{ Depressive symptomatology } & \multirow[b]{2}{*}{ F (d.f.) } \\
\hline & Lower $(\mathrm{N}=146) \mathrm{M}(\mathrm{SD})$ & Moderate $(\mathrm{N}=137) \mathrm{M}(\mathrm{SD})$ & Higher $(\mathrm{N}=118) \mathrm{M}(\mathrm{SD})$ & \\
\hline Depression (total score) & $.82(.84)$ & $5.60(1.92)$ & $17.95(7.43)$ & $560.33(2)^{* * * *}$ \\
\hline \multicolumn{5}{|l|}{ Meaning of Life } \\
\hline Contentedness with life & $.39(.66)$ & $.04(.81)$ & $-.53(1.27)$ & $3.22(2)^{* * * *}$ \\
\hline Goal achievement & $.27(.73)$ & $.06(.83)$ & $-.40(1.29)$ & $16.75(2)^{* * * *}$ \\
\hline Freedom of choice & $.09(.87)$ & $-.008(.97)$ & $-.11(1.16)$ & $1.45(2)$ \\
\hline Death & $.12(.87)$ & $-.09(.98)$ & $-.04(1.14)$ & $1.78(2)$ \\
\hline Total meaning of life & $.48(.60)$ & $.06(.73)$ & $-.68(1.24)$ & $58.15(2)^{* * * *}$ \\
\hline
\end{tabular}

Note: ${ }^{* * * *} p<.0001$. 
present statistically significant differences as to depressive symptomatology, because of the way they were selected (F[2, 398] $=560.33, p<.0001$ and $p<.0001$ for Scheffé criterion) and as to the meaning of life (total score: $\mathrm{F}[2,398]=58.15, p<.0001$ and $p<.0001$ for Scheffé criterion). More specifically, concerning the dimensions of the meaning of life, only two of them seem to differentiate, in a statistically significant way, individuals with lower, moderate and higher depressive symptomatology: "contentedness with life" $(\mathrm{F}[2,398]=33.22, p<.0001$ and $p$ $<.001$ for Scheffé criterion) and "goal achievement" $(\mathrm{F}[2,398]$ $=16.75, p<.0001$ and $p<.001$ for Scheffé criterion).

However, in contrast with the previous correlations, the differences among these three groups, except for "death", are not statistically significant even not with regards to "freedom of choice". In addition, Scheffé criterion, in the above analyses, indicated that the differences of the means among the three depression groups, studied in pairs, both regarding "contentedness with life" and "goal achievement", as well as "depresssion" and "total meaning of life", are in all combinations statistically significant. Specifically, when a group scores higher on depression from another one, it presents, in comparison to that group, a lower mean of meaning of life, considered both on the total score as well as on each dimension separately.

Finally, it is of interest to consider the relationships of the sample's demographic characteristics with depression and meaning of life. Specifically, depressive symptomatology displays statistically significant negative correlations with age (Pearson $\mathrm{r}$ $=-.13, p<.01$ ), order of an individual's birth (Pearson $\mathrm{r}=-.13$, $p<.01)$ and his/her participation in cultural, athletic, political or other activities (Spearman's rho $=-.15, p<.001$ ). An individual's sense of meaning of life is associated in a statistically significant way with both his/her participation in various activities (Spearman's rho $=.26, p<.0001$ ), and his/her marital-affective status: $\chi^{2}(2, \mathrm{n}=400)=8.39, p<.01$. For example, only $27.2 \%$ (56 individuals) of those who are married or involved in a romantic affair are found in the group with the lower meaning of life, while the respective percentage of unmarried or not in a romantic affair is of $40.7 \%$ (79 persons). In the above analysis, for the computation of the $\chi^{2}$ criterion, "meaning of life" was transformed from an ordinal into a categorical variable with three levels $(1=$ higher, $2=$ moderate and 3 = lower).

Regarding the relationship between meaning of life and psychological health, the results, as shown in Table 4, indicate a negative moderate correlation between meaning of life and total score in "G.H.Q." $(\mathrm{r}=-.55, p<.0001)$. That is, the higher the meaning of life, the better the "general health". Specifically, concerning the factors of general psychological health, the fol- lowing negative correlations have been found: 1) a moderate correlation between meaning of life and the "somatic symptoms" factor $(\mathrm{r}=-.38, p<.0001)$; consequently, the higher the meaning of life, the less the somatic symptoms; 2) a moderate correlation between meaning of life and the "anxiety/sleep disturbances" factor $(r=-.39, p<.0001)$; therefore, the higher the meaning of life, the less the anxiety; 3 ) a moderate correlation between meaning of life and the "social dysfunction" factor $(\mathrm{r}=$ $-.32, p<.0001)$; that is, the higher the meaning of life, the less the social dysfunction and 4) a strong correlation between meaning of life and the "severe depression" factor $(\mathrm{r}=-.63, p$ $<.0001)$; that is, the higher the meaning of life, the lower the depression.

In this sense, the comparison of the means concerning general psychological health between individuals with the lower and the higher meaning of life, based on their responses to the "meaning of life scale" (Table 5), indicated that individuals with the lower meaning of life showed a higher mean score on "somatic symptoms" factor $(\mathrm{M}=14.13)$, compared to individuals with the higher meaning of life $(\mathrm{M}=11.06)$ : $\mathrm{t}(195.22)=$ $6.00, \mathrm{p}<.0001$. Additionally, subjects with the lower meaning of life showed a higher mean score on "anxiety/sleep disturbances" factor $(\mathrm{M}=12.54)$, than individuals with the higher meaning of life $(\mathrm{M}=9.82)$ : $\mathrm{t}(173.34)=5.84, p<.0001$. Individuals with the lower meaning of life also had a higher mean score on "severe depression" factor $(\mathrm{M}=10.56)$, than individuals with the higher meaning of life $(\mathrm{M}=7.42): \mathrm{t}(111.21)=7.34$, $\mathrm{p}<.0001$, and scored a higher mean $(\mathrm{M}=15.34)$ when compared to individuals with the higher meaning of life $(M=13.38)$ on "social dysfunction" factor: $\mathrm{t}(214)=4.30, p<.0001$. Furthermore, individuals with the lower meaning of life showed a higher mean score on "general psychological health" factor (M $=52.49)$, than individuals with the higher meaning of life $(\mathrm{M}=$ 41.58): $\mathrm{t}(169.65)=7.42, p<.0001$.

Table 4.

Correlations between meaning of life and general psychological health.

\begin{tabular}{cc}
\hline & Meaning of Life \\
\hline General Health & $-.38^{* * * *}$ \\
Somatic symptoms & $-.39^{* * * *}$ \\
Anxiety/sleep disturbances & $-.32^{* * * *}$ \\
Social dysfunction & $-.63^{* * * *}$ \\
Severe depression & $-.55^{* * * *}$ \\
General psychological health (Total) & \\
\hline
\end{tabular}

Table 5.

Comparison of means (M) and standard deviations (SD) between persons with the lower and the higher meaning of life as to general psychological health.

\begin{tabular}{|c|c|c|c|}
\hline & Lower meaning $(\mathrm{N}=99) \mathrm{M}(\mathrm{SD})$ & Higher meaning $(\mathrm{N}=117) \mathrm{M}(\mathrm{SD})$ & \\
\hline \multicolumn{4}{|l|}{ General Health } \\
\hline Somatic symptoms & $14.13(3.98)$ & $11.06(3.44)$ & $6.00^{* * * *}$ \\
\hline Anxiety/Sleep disturbances & $12.54(3.87)$ & $9.82(2.76)$ & $5.84^{* * * *}$ \\
\hline Social dysfunction & $15.34(3.68)$ & $13.38(3.03)$ & $4.30^{* * * *}$ \\
\hline Severe depression & $10.56(4.12)$ & $7.42(1.16)$ & $7.33^{* * * *}$ \\
\hline General psychological health (total) & $94.03(12.35)$ & $129.41(8.52)$ & $7.42^{* * * *}$ \\
\hline
\end{tabular}

Note: ${ }^{* * * *} p<.0001$. 


\section{Discussion}

One of the aims of the present study was to explore the relationship between meaning of life and depression in young men in the sociocultural context of Greece. Our assumption regarding the relationship between these two variables was confirmed and showed that the higher the meaning of life of a person, the less the depressive symptomatology he/she manifests. In the same sense, the comparison between individuals with lower, medium and higher depressive symptomatology, indicated, as expected, that meaning of life is an important discriminative factor among them, in the sense that when a group has a higher level of depression than another one, it presents in comparison a lower mean score in meaning of life. Subsequently, the higher a person's sense of meaning of life, the less possible is for him/her to develop depressive symptomatology; a finding which is in accordance with the existing literature (Hart et al., 2005; Lyon \& Younger, 2001; Mascaro \& Rosen, 2005, 2008; Robak \& Griffin, 2000; Simonelli et al., 2008; Stolovy et al., 2009; Westerhof et al., 2010).

Another important issue of this study that has not yet been investigated sufficiently in the international literature, concerns the dimensions of meaning of life and how they are associated with depressive symptomatology. According to the results, it seems clear, that in fact only meaning emanated from "contentedness with life" and "goal achievement" differentiates the subjects of our sample as to their depressive symptomatology. On the contrary, meaning associated with "freedom of choice", as well as preoccupation with "death", its meaning and the way an individual gives meaning to life do not seem to be associated with depressive symptomatology. These negative results as to "freedom of choice" and "death" are explained, eventually, by the fact that our sample consists of persons of a relative young age (18 - 30 years old), in a particular period of their life, where the event that literally prevails is their obligatory military service in the navy, which is unquestionable and many might agree with this. Because of their young age, and although they are aware, eventually they haven't yet realized, considered and estimated in depth concepts like "freedom of choice" and "death", or the consequences that these concepts may have. However, this is even truer for the concept of death, the realization of which, as well as the search for meaning of life in death, are not included, developmentally, among the issues that usually preoccupy young people of post adolescence or early adulthood.

It is worthwhile to mention the relationship of depressive symptomatology with age and order of birth. Specifically, the higher a person's age and order of birth the lower his/her depressive symptomatology. As to age, our findings concur with other studies that constantly indicate that young people belong to the population with the highest risk for developing depressive symptomatology. This may be due to the fact that young people experience high levels of social pressure and stress, because during this period of age (18 to 30 years old) they are socially expected to develop successfully in almost all important domains of their life (personal, social, sentimental, vocational, financial) (Brown, Ahmed, Gary, \& Milburn, 1995; Jorm, 2000; Lu, 1995). As to the relationship between depression and order of birth, it has repeatedly been suggested that the first-born children are overcharged, due to the difference in the way their parents treat them, because of luck of prior parental experience, the greater attention they receive as well as the greater parental expectations and demands (Herrera, 2001; Herrera, Zajonc, \& Wieczorkowska, 2003; Saroglou \& Fiasse, 2003; Whiteman, McHale, \& Crouter, 2003).

Finally, a finding of special interest is the significant association between the increase of a person's participation in several social, political, athletic and cultural activities and the reduction of depressive symptomatology and mainly the increase of meaning of life. The relationship between activities and meaning of life constitutes, probably, the intermediate link, which allows a better and probably a more complete, interpretation of the repeatedly ascertained relationship between activities (pleasant or not) and depression (Kleftaras, 2000; Logsdon \& Teri, 1997; Meeks \& Depp, 2002). In other words, a person's involvment in any kind of activities, seems to be an important source of meaning, which exactly for that reason (increased sense of meaning) may, eventually, lead to reduced depressive symptomatology. The significant relationship between a person's marital status and meaning of life that he/she experiences can also be explained in the same way. Being married or in a romantic affair seems to be an important source of support and meaning. This interpretation, though, as to both marital status and participation in activities should be investigated systematically in future studies.

Regarding the relationship between meaning of life and psychological well-being/health in newly recruited young men for their national service in the Greek navy, our initial hypothesis was confirmed. Specifically, a statistically significant negative relationship has been found between meaning of life and general psychological health, somatic symptoms, anxiety and sleep disturbances, social dysfunction and severe depression. In other words, the higher an individual's meaning of life, the better his/her psychological health, sense of personal health level, social functioning and the lower his/her anxiety, sleep disturbances and depressive symptoms. In addition, the comparison of the mean scores between individuals with higher and lower meaning of life, indicated, as expected, that the individuals with higher meaning of life differ significantly in all the above factors, when compared with those of lower meaning in life, showing much better scores in their general psychological health.

In this sense, it is not surprising that individuals with higher meaning of life differed significantly from those with lower meaning of life, with regards to depression as measured by General Health Questionnaire. In other words, it seems that individuals experiencing a more intense sense of meaning in their life, in contrast with those with lower meaning of life, have a positive perception for their personal health level, they experience lower anxiety and sleep disturbances, they are more socially functional and they have a better psychological health, as reflected by the definite lower depressive symptomatology they mention. Therefore, meaning of life is significantly associated with general psychological health.

The conclusions of the present study are limited by the fact that women are not included in the sample, but only young men in the context of their military service in the Navy, who volunteered to participate in this study and who do not present clinically diagnosed depression. Moreover, the population of newly recruited men, at that particular period of their life, may differ from the rest of the population of young people. Their shared experience-i.e., training in Army Navy - may tend to incline them to a more or less shared view on meaning of life; a fact that does not allow to consider these two populations as identi- 
cal (equivalent), even if the age criterion is respected. Therefore, the results cannot be generalized to the general population or to a sample manifesting clinically diagnosed depression. Although this sample cannot be considered as representative of the wider population of young people, it may though be considered far representative of the general population of the newly recruited men for military service in the Navy. Consequently, further studies with various and more representative populations and especially with clinical samples, would lead to better and more reliable data. Additionally, we should mention that the measures used at the present study, though adapted in Greek and with good reliability and factorial structure, still, they haven't been standardized in Greece. Furthermore, they are all selfreports and consequently the effects of "social desirability" cannot be ruled out.

An additional limitation of this study is the correlational nature of the results. The undoubted relationships between the variables, though ascertained, don't allow "cause and effect" conclusions, regarding the relationship between depression and meaning of life. Although the dominant view, to which we subscribe, is that the concept of meaning of life affects psychological well-being in general and especially depression, however, it is also possible that a person's depressive symptomatology may affect his/her perception of what is meaningful and how much. The data of this study are not sufficient for answering this question, which still remains open for future investigation.

Despite the abovementioned limitations, we consider that the results of the present study are important, as they confirm the relationship between meaning of life and depression. This fact renders imperative the need for a revisal of the often suggested view, that meaning of life is nothing more than a philosophical concept, which may be overlooked in the context of psychotherapeutic process (Debats, 1996; Rufflin, 1984). It is also important, if reconfirmed by other studies, that among meaning of life dimensions, those of great importance in eliciting depressive symptomatology (at least in young men) seem to be "contentedness with life" and "goal achievement". Consequently, these two dimensions in combination with the situation of marriage (or the existence of a romantic relationship) and participation in several social, political, athletic and cultural activities, as sources of meaning, should be considered and utilized when coping therapeutically with depressive symptomatology.

The relationship between meaning of life and depression is a complex one and many other issues concerning meaning of life should also be investigated in future studies. As seen previously, it is interesting and useful in psychotherapeutic terms to investigate which are the personal sources of meaning, how they are created and how they can be cultivated. A person can find meaning of life from many and different sources. The fact, however that some of them may promote psychological health, while others may foster the development of psychopathology and more specifically depressive symptomatology, renders necessary and essential an in depth study of their effects.

Another important issue for research is how and through which mechanism meaning of life comes to influence the psychological health and more specifically depressive symptomatology. According to some studies meaning of life seems to have a direct influence on health, psychological adjustment and well-being (Chou, 2000; Compton, 2000; Desormeaux, 2000; Labelle et al., 2001; Moomal, 1999; Smith \& Zautra, 2004;
Thompson, Coker, \& Krause, 2003), while according to others it acts as a mediator (Harlow, Newcomb, \& Bentler, 1986; Heisel \& Flett, 2004; Newcomb \& Harlow, 1986). Finally, an issue that comes up and hasn't yet been understood is why some people tend to seek for meaning, especially in difficult situations, while others do not. It is possible that some temperament characteristics or personality traits predispose some persons for meaning seeking, which, however, have not been studied yet.

Our hypotheses regarding the relationship between meaning of life and general psychological health were confirmed. It would be interesting for future studies in the field of psychological health to consider the way that existential theory interprets and explains human behavior, as it seems a very promising theoretical approach, mainly in regard to the understanding and coping with depressive symptomatology. Moreover, it is of interest to study the concept of meaning of life in relation to psychopathology and its comparison with respective data in general population as well as a more systematic investigation of meaning of life regarding specific personality traits and personal values.

\section{REFERENCES}

Arrindell, W. A., Steptoe, A. A., \& Wardle, J. J. (2003). Higher levels of state depression in masculine than in feminine nations. Behaviour Research and Therapy, 41, 809-817. doi:10.1016/S0005-7967(02)00185-7

Brown, D. R., Ahmed, F., Gary, L. E., \& Milburn, N. G. (1995). Major depression in a community sample of African Americans. American Journal of Psychiatry, 152, 373-378.

Centers for Disease Control and Prevention (CDC) (2000). National center for injury prevention and control. URL (last checked 1 February 2008). http://www.cdc.gov/ncipc/pub-res/youthsui.htm

Chamberlain, K., \& Zika, S. (1988). Measuring meaning in life: An examination of three scales. Personality and Individual Differences, 9, 589-596. doi:10.1016/0191-8869(88)90157-2

Chan, D. W. (2009). Orientations to happiness and subjective wellbeing among Chinese prospective and in-service teachers in Hong Kong. Educational Psychology, 29, 139-151. doi: $10.1080 / 01443410802570907$

Chou, K.-L. (2000). Intimacy and psychosocial adjustment in Hong Kong Chinese adolescents. Journal of Genetic Psychology, 161, 141151. doi: $10.1080 / 00221320009596701$

Compton, W. C. (2000). Meaningfulness as a mediator of subjective well-being. Psychological Reports, 87, 156-160.

Coyle, B. (1998). Restoring meaning and purpose after the death of a child: A qualitative psychological study. Dissertation Abstracts International: Section B: The Sciences \& Engineering, 59, 1363.

Crumbaugh, J. C. (1968). Cross-validation of Purpose in Life Test based on Frankl's concepts. Journal of Individual Psychology, 24, 74-81.

Crumbaugh, J. C., \& Maholick, L. T. (1964). An experimental study in existentialism: The psychometric approach to Frankl's concept of noogenic neurosis. Journal of Clinical Psychology, 20, 589-596.

Crumbaugh, J. C., \& Maholick, L. T. (1969). Manual of instructions for the Purpose-in-Life-Test. Munster: Psychometric Affiliates.

Debats, D. L. (1996). Meaning in life: Clinical relevance and predictive power. British Journal of Clinical Psychology, 35, 503-516. doi:10.1111/j.2044-8260.1996.tb01207.x

Desormeaux, L. (2000). Meaning: Relationship to coping mechanisms and well-being. Dissertation Abstracts International: Section B: The Sciences \& Engineering, 61, 3274.

Fitzpatrick, J. J. (2009). Preventing suicide: Developing meaning in life. Archives of Psychiatric Nursing, 23, 275-276. doi:10.1016/j.apnu.2009.06.002

Florkowski, A., Gruszczynski, W., \& Wawrzyniak, Z. (2001). Evaluation of psychopathological factors and origins of suicides committed 
by soldiers. Military Medicine, 166, 44-47.

James, F. A. P., \& Leung, N. (2009). Existential well-being in younger and older people with anorexia nervosa-A preliminary investigation. European Eating Disorders Review, 17, 24-30.

Frankl, V. (1959). Man's search for meaning. London: Hodder \& Stoughton.

Frankl, V. (1967). Psychotherapy and existentialism: Selected papers on logotherapy. New York: Simon and Schuster.

Frankl, V. (1969). The will to meaning: Foundations and applications of logotherapy. New York: Meridian.

Frankl, V. (1973). The doctor and the soul. From psychotherapy to logotherapy. New York: Random House.

Garfield, C. A. (1973). A psychometric and clinical investigation of Frankl's concept of existential vacuum and of anomia. Psychiatry, 36, 396-408.

Garyfalos, G., Karastergiou, I., \& Adamopoulou, M. (1991). Greek version of the General Health Questionnaire: Accuracy of translation and validity. Acta Psychiatrica Scandinavica, 84, 371-378. doi:10.1111/j.1600-0447.1991.tb03162.x

Goldberg, D. P., \& Hillier, V. F. (1979). A scaled version of the General health Questionnaire. Psychological Medicine, 9, 139-145. doi:10.1017/S0033291700021644

Goldberg, D. P., \& Williams, E. (1988). A user's guide to the G.H.Q. Windsor: NFER-Nelson.

Halama, P., \& Dedova, M. (2007). Meaning in life and hope as predictors of positive mental health: Do they explain residual variance not predicted by personality traits? Studia Psychologica, 49, 191-200.

Harlow, L. L., Newcomb, M. D., \& Bentler, P. M. (1986). Depression, self-derogation, substance use, and suicide ideation: Lack of purpose in life as a mediational factor. Journal of Clinical Psychology, 42, $5-21$.

doi:10.1002/1097-4679(198601)42:1<5::AID-JCLP2270420102>3.0 .CO;2-9

Hart, S., Fonareva, I., Merluzzi, N., \& Mohr, D. C. (2005). Treatment for depression and its relationship to improvement in quality of life and psychological well-being in multiple sclerosis patients. Quality of Life Research, 14, 695-703. doi:10.1007/s11136-004-1364-Z

Heisel, M. J., \& Flett, G. L. (2004). Purpose in life, satisfaction with life, and suicide ideation in a clinical sample. Journal of Psychopathology \& Behavioral Assessment, 26, 127-135. doi:10.1023/B:JOBA.0000013660.22413.e0

Herrera, N. C. (2001). Birth rank and personality: Beliefs and their consequences. Dissertation Abstracts International: Section B: The Sciences \& Engineering, 61, 5054.

Herrera, N. C., Zajonc, R. B., \& Wieczorkowska, G. (2003). Beliefs about birth rank and their reflection in reality. Journal of Personality \& Social Psychology, 85, 142-150. doi:10.1037/0022-3514.85.1.142

Ho, M. Y., Cheung, F. M., \& Cheung, S. F. (2010). The role of meaning in life and optimism in promoting well-being. Personality and Individual Differences, 48, 658-663. doi:10.1016/j.paid.2010.01.008

Holahan, C. K., Holahan, C. J., \& Suzuki, R. (2008). Purposiveness, physical activity, and perceived health in cardiac patients. Disability and Rehabilitation, 30, 1772-1778. doi:10.1080/10428190701661508

Jaarsma, T. A., Pool, G., Ranchor, A. V., \& Sanderman, R. (2007). The concept and measurement of meaning in life in Dutch cancer patients. Psycho-Oncology, 16, 241-248. doi:10.1002/pon.1056

James, A. (1993). Evolution des conduites suicidaires dans les armées en France. Psychologie Médicale, 25, 325-327.

Jorm, A. F. (2000). Does old age reduce the risk of anxiety and depression? A review of epidemiological studies across the adult life span. Psychological Medicine, 30, 11-22. doi:10.1017/S0033291799001452

Kang, K. A., Shim, J. S., Jeon, D. G., \& Koh, M. S. (2009). The effects of logotherapy on meaning in life and quality of life of late adolescents with terminal cancer. Journal of Korean Academy of Nursing, 39, 759-768. doi:10.4040/jkan.2009.39.6.759

Kendricks, L., Anderson, N., \& Moore, B. (2007). Perceptions of depression among young African American men. Family and Commu- nity Health, 30, 63-73.

Kessler, R., \& Walters, E. (1998). Epidemiology of DSM-III-R major depression and minor depression among adolescents and young adults in the National Comorbidity Survey. Depression Anxiety, 7, 3-14.

doi:10.1002/(SICI)1520-6394(1998)7:1<3::AID-DA2>3.0.CO;2-F

Kleftaras, G. (2000). Interpersonal problem-solving of means-ends thinking, frequency and strength of pleasant and unpleasant activities and symptoms of depression in French older adults. Physical and Occupational Therapy in Geriatrics, 17, 43-63. doi: 10.1080/J148v17n04 04

Kleftaras, G., \& Tzonichaki, I. (2010). Perceived locus of control and depression among Greek young and older adults. Review of Counselling and Guidance, 91-92, 33-46.

Kleftaras, G., \& Tzonichaki, I. (2012). Questionnaire d'auto-evaluation de la symptomatologie dépressive [in Greek]. In A. Stalikas, S. Triliva, \& P. Roussi (Eds.), The psychometric tools in Greece. Athens: Ellinika Grammata.

Kleftaras, G., \& Psarra, E. (2012). Purpose in life test [in Greek]. In A. Stalikas, S. Triliva, \& P. Roussi (Eds.), The psychometric tools in Greece. Athens: Ellinika Grammata.

Kleftaras, G., \& Psarra, E. (in press). Meaning in life: Scale's facto-rial structure and psychological well-being [in Greek]. Review of Counselling and Guidance.

Klerman, G. (1988). The current age of youthful melancholia. Evidence for increase in depression among adolescents and young adults. British Journal of Psychiatry, 152, 4-14. doi:10.1192/bjp.152.1.4

Klerman, G., \& Weissman, M. (1989). Increasing rates of depression. Journal of the American Medical Association, 262, 2229-2235. doi:10.1001/jama.1989.03420150079041

Krause, N. (2009). Meaning in life and mortality. Journals of Gerontology: Series B: Psychological Sciences and Social sciences, 64, 517-527. doi:10.1093/geronb/gbp047

Labelle, R., Alain, M., Bastin, E., Bouffard, L., Dube, M., \& Lapierre, S. (2001). Well-being and psychological stress: Toward a hierarchical, cognitive-affective model in mental health. Revue Quebecoise de Psychologie, 22, 71-87.

Lethborg, C, Aranda, S., Cox, S., \& Kissane, D. (2007). To what extent does meaning mediate adaptation to cancer? The relationship between physical suffering, meaning in life, and connection to others in adjustment to cancer. Palliative \& Supportive Care, 5, 377-388. doi: $10.1017 / \mathrm{S} 1478951507000570$

Logsdon, R. G., \& Teri, L. (1997). The pleasant events schedule-AD: Psychometric properties and relationship to depression and cognition in Alzheimer's disease patients. Gerontologist, 37, 40-45. doi:10.1093/geront/37.1.40

Lu, L. (1995). Life events, social support, and depression among Taiwanese female. Journal of Social Psychology, 135, 185-190. doi: $10.1080 / 00224545.1995 .9711422$

Lyon, D. E. (1997). A causal model of the effects of existential wellbeing on the relationship between severity of human immunodeficiency virus (HIV) disease and depression. Dissertation Abstracts International: Section B: The Sciences \& Engineering, 58, 1214.

Lyon, D. E., \& Younger, J. B. (2001). Purpose in life and depressive symptoms in persons living with HIV Disease. Journal of Nursing Scholarship, 33, 129-133. doi:10.1111/j.1547-5069.2001.00129.x

Maddi, S. R. (1967). The existential neurosis. Journal of Abnormal Psychology, 72, 311-325. doi:10.1037/h0020103

Mascaro, N., \& Rosen, D. H. (2005). Existential meaning's role in the enhancement of hope and prevention of depressive symptoms. Journal of Personality, 73, 985-1013. doi:10.1111/j.1467-6494.2005.00336.x

Mascaro, N., \& Rosen, D. H. (2008). Assessment of existential meaning and its longitudinal relations with depressive symptoms. Journal of Social and Clinical Psychology, 27, 576-599. doi:10.1521/jscp.2008.27.6.576

Meeks, S., \& Depp, C. A. (2002). Pleasant events-based behavioral interventions for depression in nursing residents: A conceptual and empirical foundation. Clinical Gerontologist, 25, 125-148. doi:10.1300/J018v25n01_07 
Meier, A., \& Edwards, H. (1974). Purpose in life test: Age and sex differences. Journal of Clinical Psychology, 30, 384-386. doi:10.1002/1097-4679(197407)30:3<384::AID-JCLP2270300351> 3.0.CO;2-V

Moomal, Z. (1999). The relationship between meaning in life and mental well-being. South African Journal of Psychology, 29, 36-41.

Newcomb, M. D., \& Harlow, L. L. (1986). Life events and substance use among adolescents: Mediating effects of perceived loss of control and meaninglessness in life. Journal of Personality and Social Psychology, 51, 564-577. doi:10.1037/0022-3514.51.3.564

Owens, G. P., Steger, M. F., Whitesell, A. A., \& Herrera, C. J. (2009). Posttraumatic stress disorder, guilt, depression, and meaning in life among military veterans. Journal of Traumatic Stress, 22, 654-657.

Pichot, P., Boyer, P., Pull, C. B., Rein, W., Simon, M., \& Thibault, A. (1984). Un questionnaire d'auto-évaluation de la symptomatologie dépressive, le questionnaire QD2, I. Construction, structure factorielle et propriétés métrologiques. Revue de Psychologie Appliquée, 34, 229-250.

Prior, P. M. (1999). Gender and mental health. Basingstoke and London: Macmillan Press.

Reinherz, H., Giaconia, R., Hauf, A., Wasserman, M., \& Paradis, A. (2000). General and specific childhood risk factors for depression and drug disorders by early adulthood. Journal of the American Academy of Child Adolescent Psychiatry, 39, 223-231. doi:10.1097/00004583-200002000-00023

Reker, G. T., \& Cousins, J. B. (1979). Factor structure, construct validity and reliability of the Seeking of Noetic Goals (SONG) and Purpose in Life (PIL) Tests. Journal of Clinical Psychology, 35, 85-91. doi:10.1002/1097-4679(197901)35:1<85::AID-JCLP2270350110>3. $0 . \mathrm{CO} ; 2-\mathrm{R}$

Robak, R. W., \& Griffin, P. W. (2000). Purpose in life: What is its relationship to happiness, depression, and grieving? North American Journal of Psychology, 2, 113-119.

Routledge, C., \& Juhl, J. (2010). When death thoughts lead to death fears: Mortality salience increases death anxiety for individuals who lack meaning in life. Cognition and Emotion, 24, 848-854. doi:10.1080/02699930902847144

Rufflin, J. E. (1984). The anxiety of meaninglessness. Journal of Counseling and Development, 63, 40-42. doi:10.1002/j.1556-6676.1984.tb02678.x

Saroglou, V., \& Fiasse, L. (2003). Birth order, personality, and religion: A study among young adults from a three-sibling family. Personality \& Individual Differences, 35, 19-29. doi:10.1016/S0191-8869(02)00137-X

Shek, D. T. L. (1992). Meaning in life and psychological well-being: An empirical study using the Chinese version of the Purpose in Life Questionnaire. The Journal of Genetic Psychology, 153, 185-200.
Simonelli, L. A., Fowler, J., Maxwell, G. L., \& Andersen, B. L. (2008). Physical sequelae and depressive symptoms in gynecologic cancer survivors: Meaning in life as a mediator. Annals of Behavioral Medicine, 35, 275-284. doi:10.1007/s12160-008-9029-8

Smith, B. W., \& Zautra, A. J. (2004). The role of purpose in life in recovery from knee surgery. International Journal of Behavioral Medicine, 11, 197-202. doi:10.1207/s15327558ijbm1104_2

Stolovy, T., Lev-Wiesel, R., Adiel, D., \& Gelkopf, M. (2009). The meaning in life for hospitalized patients with schizophrenia. Journal of Nervous and Mental Disease, 197, 133-135. doi:10.1097/NMD.0b013e3181963ede

Thompson, E. H. Jr., Noone, M. E., \& Guarino, A. B. (2003). Widows' spiritual journeys: Do they quest? [special issue]. Journal of Religious Gerontology, 14, 119-138. doi:10.1300/J078v14n02 03

Thompson, N. J., Coker, J., \& Krause, J. S. (2003). Purpose in life as a mediator of adjustment after spinal cord injury. Rehabilitation Psychology, 48, 100-108. doi:10.1037/0090-5550.48.2.100

Tzonichaki, I., \& Kleftaras, G. (1998). Etude comparative entre sujets jeunes et âgés, concernant la dépression et le "lieu de contrôle". Journal d'Ergothérapie, 20, 49-55.

Visser, A., Garssen, B., \& Vingerhoets, A. (2010). Spirituality and well-being in cancer patients: A review. Psycho-Oncology, 19, 565572. doi:10.1002/pon. 1626

Waite, R., \& Calamaro, C. (2009). Cultural competency-Culture and depression: A case example of a young african american man. Perspectives in Psychiatric Care, 45, 232-238. doi:10.1111/j.1744-6163.2009.00226.x

Westerhof, G. J., Bohlmeijer, E. T., Van Beljouw, I. M. J., \& Margriet, A. (2010). Improvement in personal meaning mediates the effects of a life review intervention on depressive symptoms in a randomized controlled trial. Gerontologist, 50, 541-549. doi:10.1093/geront/gnp168

Whiteman, S. D., McHale, S. M., \& Crouter, A. C. (2003). What parents learn from experience: The first child as a first draft? Journal of Marriage \& Family, 65, 608-621. doi:10.1111/j.1741-3737.2003.00608.x

Yang, W., Staps, T., \& Hijmans, E. (2010). Existential crisis and the awareness of dying: The role of meaning and spirituality. OmegaJournal of Death and Dying, 61, 53-69. doi:10.2190/OM.61.1.c

Young, A., Klap, R., Sherbourne, C., \& Wells, K. (2001). The quality of care for depressive and anxiety disorders in the United States. Archives of General Psychiatry, 58, 55-61. doi:10.1001/archpsyc. 58.1 .55

Zeitchik, G. (2001). The construct validity of the purpose in life test: Quantifying Victor Frankl's "Will to Meaning". Dissertation $A b$ stracts International: Section B: The Sciences \& Engineering, 61, 5049 . 